\title{
Problems with models assessing influences of tree size and inter-tree competitive processes on individual tree growth: a cautionary tale
}

\author{
P. W. West ${ }^{1}$ - D. A. Ratkowsky ${ }^{2}$
}

Received: 12 July 2021 / Accepted: 26 August 2021 / Published online: 4 October 2021

(C) The Author(s) 2021

\begin{abstract}
In forest growing at any one site, the growth rate of an individual tree is determined principally by its size, which reflects its metabolic capacity, and by competition from neighboring trees. Competitive effects of a tree may be proportional to its size; such competition is termed 'symmetric' and generally involves competition below ground for nutrients and water from the soil. Competition may also be 'asymmetric', where its effects are disproportionate to the size of the tree; this generally involves competition above ground for sunlight, when larger trees shade smaller, but the reverse cannot occur. This work examines three model systems often seen as exemplars relating individual tree growth rates to tree size and both competitive processes. Data of tree stem basal area growth rates in plots of evenaged, monoculture forest of blackbutt (Eucalyptus pilularis Smith) growing in sub-tropical eastern Australia were used to test these systems. It was found that none could distinguish between size and competitive effects at any time in any one stand and, thus, allow quantification of the contribution
\end{abstract}

Project funding: No funding was provided for this project.

The online version is available at http://www.springerlink.com

Corresponding editor: Yu Lei.

Supplementary Information The online version contains supplementary material available at https://doi.org/10.1007/ s11676-021-01395-9.

\section{P. W. West}

pwest@nor.com.au

1 Forest Research Centre, Southern Cross University, Lismore, NSW, Australia

2 Tasmanian Institute of Agriculture, University of Tasmania, Hobart, TAS, Australia of each to explaining tree growth rates. They were prevented from doing so both by collinearity between the terms used to describe each of the effects and technical problems involved in the use of nonlinear least-squares regression to fit the models to any one data set. It is concluded that quite new approaches need to be devised if the effects on tree growth of tree size and competitive processes are to be quantified and modelled successfully.

Keywords Symmetric competition · Asymmetric competition $\cdot$ Tree growth rate $\cdot$ Growth modeling . Nonlinear modeling

\section{Introduction}

Given a forest growing on a particular site, with particular climatic characteristics and soil fertility, the growth rate at any time of a tree will depend, firstly, on its size (Pretzsch et al. 2012; Cordonnier et al. 2019; Ogawa 2019; Pretzsch 2021) and, in particular, the amount of living tissues that it has accumulated to undertake metabolic processes. This growth rate will decline as the tree grows larger, possibly as a result of greater respiratory demands to maintain and renew its live tissues (West 2020). Some systems relating tree growth rates to tree size have functional forms that assumes this decline occurs (e.g. Papaik and Canham 2006; Yang et al. 2009; Acquah and Marshall 2020). A second determinant of the growth of a tree will be its genetic makeup and concomitant physiological capabilities (von Wuehlisch et al. 1990); these effects will be more pronounced between trees of different species (e.g. Bosela et al. 2019; Fien et al. 2019; Orman et al. 2021).

A third factor then affecting growth rates will be the amounts of light, water and nutrients each tree can obtain 
Table 1 Symbols used here and their meanings

\begin{tabular}{|c|c|c|c|}
\hline Symbol & How computed & Units & Meaning \\
\hline$n$ & & & Number of individual trees in a plot \\
\hline$B_{\mathrm{i}}$ & & $\mathrm{m}^{2}$ & Basal area of the $i$ th tree in plot at the start of the growth period concerned \\
\hline $\mathrm{d} B_{\mathrm{i}} / \mathrm{dt}$ & & $\mathrm{m}^{2} \mathrm{a}^{-1}$ & Basal area growth rate of the $i$ th tree in plot over the growth period \\
\hline$B$ & $\left(\sum_{i=1 \ldots \mathrm{n}} B_{i}^{2 / 3}\right) / n$ & $\mathrm{~m}^{2 / 3}$ & Average of tree basal areas raised to the power $2 / 3$ \\
\hline $\mathrm{B}_{T}$ & $\sum_{i=1 \ldots n} B_{i}$ & $\mathrm{~m}^{2}$ & Total basal area of trees in plot \\
\hline$B_{L i}$ & $\Sigma_{j=1 \ldots n} B_{j}$ for $B_{j} \geq B_{i}$ & $\mathrm{~m}^{2}$ & $\begin{array}{l}\text { Total basal area of trees in plot with basal areas equal to, or greater than, that of the } \\
i \text { th tree }\end{array}$ \\
\hline$B_{O i}$ & $\sum_{j=1 \ldots n, j \neq i} B_{j}$ & $\mathrm{~m}^{2}$ & Total basal area of trees in plot excluding that of the $i$ th tree \\
\hline$K$ & $\pi / 40,000$ & $\mathrm{~m}^{2} \mathrm{~cm}^{-2}$ & Factor to convert tree diameter at breast height $(\mathrm{cm})$ to tree basal area $\left(\mathrm{m}^{2}\right)$ \\
\hline$\sigma_{i}^{2}$ & & $m^{4} a^{-2}$ & $\begin{array}{l}\text { Estimate of residual variance for a tree of size } B i \text { from fitting Eqs. 2, } 7 \text { or } 12 \\
\text { (Table 2) with unweighted least-squares linear regression }\end{array}$ \\
\hline $\begin{array}{l}a, b, \rho, \psi, p, q, \lambda_{1}, \lambda_{2}, \lambda_{3} \\
\quad \lambda_{4}, \mathrm{~m}, \alpha, \alpha_{\mathrm{I}}, \alpha_{0}, \alpha_{1}, \alpha_{2}, \\
\quad \alpha_{3}, \alpha_{4}\end{array}$ & & & Model parameters \\
\hline
\end{tabular}

from the site for its metabolic purposes. Where trees are growing in close proximity to one another, the regions around each from which they might gather those resources may overlap. The ability of a tree to then compete with its neighbors for access to those resources will determine how well it can grow subsequently.

Considerable study has been made of how competitive processes between plants operate. There are many reviews of this work (Berger et al. 2008; Pretzsch et al. 2012; Craine and Dybzinski 2013; Cordonnier and Kunstler 2015; Fernández-Tschieder and Binkley 2018; Pommerening and Meador 2018; Forrester 2019; Pommerening and Grabarnik 2019). Rasmussen and Weiner (2017, Table 1) have offered the most recent definitions of the two forms of competitive processes that are believed to operate within a plant stand, 'symmetric' and 'asymmetric' competition. Symmetric competition varies from 'absolute symmetry', where all plants take up the same amount of resources and each grows at the same rate irrespective of its size, to 'relative size symmetry', where plants take up resources and grow at rates directly proportional to their sizes. Asymmetric competition varies from 'partial size asymmetry', where resource uptake and growth proceed at rates disproportionately large with respect to tree size to 'absolute size asymmetry', where the largest plants take up all the resources and they are the only ones that grow.

Competition for water and nutrients below ground is most commonly symmetric, because individuals are able to take up amounts of those in proportion to the size and spread of their root systems; occasionally asymmetric competition below ground has been observed (Hodge 2006; Schenk 2006; Lei et al. 2012; Brown et al. 2019; Rasmussen et al. 2019). Above ground, competition is principally asymmetric for light when taller (larger) trees may shade smaller, but the reverse cannot occur; canopy abrasion of smaller tree crowns by larger tree crowns has also been observed as an asymmetric competitive effect (Hajek et al. 2015). A model system of forest growth (Binkley 2004; Binkley et al. 2006; Fernández-Tschieder and Binkley 2018; Forrester 2019; Fernández-Tschieder et al. 2020) describes how competitive processes develop over time as a forest grows. At the earliest stages of growth, individual seedlings have canopies and root systems that are too small to interact with those of their neighbours. As they grow, root systems start to overlap and symmetric competition below ground starts. Later, some trees become tall enough to shade others and asymmetric competition above ground for light starts. At the oldest stage, smaller trees will have died and only the largest trees remain; these then continue to compete with each other symmetrically below ground. However, in general, at any stage of development of a forest, 'the overall expression of competition is a mixture of asymmetric and symmetric' (Wichmann 2001).

It seems clear also that the level of symmetric and asymmetric competitive processes operating at any time in a stand may vary, depending on the availability of resources at that time. When environmental circumstances are less favourable, such as when rainfall is low, on less fertile sites or where light availability is low, symmetric competition for below ground resources tends to be relatively more influential in determining growth than asymmetric competition above-ground for light (Wichmann 2001; Copenhaver-Parry and Cannon 2016; Pretzsch and Biber 2010; Pretzsch et al. 2012; Calama et al. 2019; Marqués et al. 2021).

These growth behaviour and competitive processes seem to operate clearly in even-aged, monoculture forest growing on a particular site. However, in the more complex, unevenaged, mixed species forests, the differences between species of their physiological and morphological characteristics, such as shade tolerance or root or crown development, affect 
how, when and how effectively trees may compete with each other (Papaik and Canham 2006; Pretzsch and Biber 2010; Pretzsch et al. 2012, 2018; Craine and Dybzinski 2013; Cordonnier and Kunstler, 2015; Guo et al. 2017; Cordonnier et al. 2018; Pommerening and Meador 2018; Brown et al. 2019; Acquah and Marshall 2020; Wu et al. 2020; Orman et al. 2021).

Over many years and for many forest types around the globe, growth models have been developed to predict individual tree growth rates in relation to tree size and the competitive pressures to which they are subject. The major texts of Weiskittel et al. (2011, Chaps. 2, 5) and Burkhart and Tomé $(2012$, Chaps. 9, 14) offer substantial reviews of this work. Often, these models predict growth with sufficient precision of estimates for the purposes of practical forest management. However, they do not generally have a form that attempts to discriminate clearly between the effect on the growth rate of a tree of its size and of the level of each of the symmetric and asymmetric competitive processes to which it is being subjected. If they did so, they might give useful information about how each of those processes affect growth and lead ultimately to even better tree growth models.

However, there are a few individual tree growth model systems that have incorporated terms aimed at describing each of tree size and competitive effects separately. The present work examines three such model systems to assess how successfully this has been done. These three have been cited frequently in other works, either to justify theories relating to growth behavior of trees in forests or to inform studies of competitive interactions. All three are applied here to growth of individual trees in each of a set of plots in evenaged, monoculture forest of blackbutt (Eucalyptus pilularis Smith) growing in sub-tropical eastern Australia. Attention is given to difficulties that may be encountered in fitting the models, to determine if they fit the data well and if they offer opportunity to quantify the extent to which tree size and competitive processes separately influence tree growth rates.

\section{Materials and methods}

\section{Models}

The first of the three model systems considered specifically here (with several references to it given in parentheses) was that of Aikman and Watkinson (1980) (referred to later as A-W) (West and Borough 1983; Perry 1985; Yokozawa and Hara 1992; Ishihara et al. 2016; Rasmussen and Weiner 2017; Mrad et al. 2020). The second was that of Coomes and Allen (2007) (C-A) (Takahashi 2010; Cordonnier and Kunstler 2015; Copenhaver-Parry and Cannon 2016; Looney et al. 2018; Guo et al. 2017; Calama et al. 2019; Nong et al. 2019; Ogawa 2019; West and Smith 2019; Marqués et al.
2021; Orman et al. 2021). The third was that of Cordonnier and Kunstler (2015) (C-K) (Glencross et al. 2016; Pommerening et al. 2016; Cordonnier et al. 2018, 2019; FernándezTschieder and Binkley 2018; Looney et al. 2018; West and Smith 2019; Zhang et al. 2020).

As is common in individual tree growth models, these models were designed to relate individual tree growth rates, over periods of perhaps $1-5$ years, to tree size at the start of the growth period, to variables termed 'competition indices' that aim to describe the competitive processes that affect growth of each tree and perhaps also to environmental conditions of the site on which each tree is growing. Competition indices may be 'distance-dependent', that is their formulation depends on the size characteristics of a tree and the sizes of and distances to its neighbours, or 'distance-independent' where the distances to its neighbours have not been measured. Further, their formulation may involve only neighbours that are larger than a subject tree, when it is then assumed they reflect the level of asymmetric competitive pressure to which the tree is being subjected. Otherwise, they may involve trees of all sizes, then reflecting symmetric competitive processes. Various competition indices that have been used are described in detail by Weiskittel et al. (2011, Chap. 2) and Burkhart and Tomé (2012, Chap. 9). All three of the model systems considered here are unusual in that they include two competition indices, one to describe symmetric competitive processes and the other to described asymmetric; the indices used are distance-independent in all three.

In its original formulation, the A-W model system used plant biomass to represent plant size and to describe growth rates, whilst the $\mathrm{C}-\mathrm{A}$ and $\mathrm{C}-\mathrm{K}$ model systems both used stem diameter at breast height $(1.3 \mathrm{~m})$. To bring commonality to the present comparisons, stem basal area (stem cross sectional area at breast height) was used as the measure of tree size and its change over a few years was used to describe tree growth. For the A-W system, this invoked the common assumption that tree biomass is related closely to stem basal area (West 2015, Chap. 7). For both the C-A and C-K systems, it was straightforward to convert their formulations to replace stem diameter with stem basal area. The symbols used in the present work and definitions of terms are given in Table 1 . The three model systems, as formulated originally and after conversion here to tree basal area, are shown as Eqs. 1, 6 and 11, respectively, in Table 2.

The A-W model system was designed to predict individual plant growth at a single site. It was tested by Aikman and Watkinson themselves and by Mrad et al. (2020) in simulation studies, where the authors chose the tree circumstances and the model parameter values, rather than applying it to an observed data set. The $\mathrm{C}-\mathrm{A}$ and $\mathrm{C}-\mathrm{K}$ model systems were designed originally to use data that included individual tree growth rates from many stands spread over a large forest area, where environmental circumstances might 
Table 2 Various model forms used here as derived from the model systems of Aikman and Watkinson (A-W), Coomes and Allen (C-A) and Cordonnier and Kunstler (C-K). Note that $\ln (\cdot)$ denotes natural logarithms

\begin{tabular}{|c|c|c|}
\hline Models & Model & Eq. no. \\
\hline \multirow[t]{5}{*}{ A-W model system } & $\mathrm{d} B_{i} / \mathrm{d} t=a B_{i}^{2 / 3} /\left[1+(n \bar{B})^{\rho}\left(\bar{B} / B_{i}^{2 / 3}\right)^{\psi}\right]-b B_{i}^{2}$ & $1^{1}$ \\
\hline & $\mathrm{d} B_{i} / \mathrm{d} t=(a / 2) B_{i}^{2 / 3}-b B_{i}^{2}$ & $2^{2}$ \\
\hline & $\mathrm{d} B_{i} / \mathrm{d} t=a B_{i}^{2 / 3} /\left[1+B_{i}^{\rho}\right]-b B_{i}^{2}$ & $3^{3}$ \\
\hline & $\mathrm{d} B_{i} / \mathrm{d} t=a B_{i}^{2 / 3} /\left[1+\left(\bar{B} / B_{i}^{2 / 3}\right)^{\psi}\right]-b B_{i}^{2}$ & $4^{4}$ \\
\hline & $\mathrm{d} B_{i} / \mathrm{d} t=a B_{i}^{2 / 3} /\left[1+B_{i}^{\rho}\left(\bar{B} / B_{i}^{2 / 3}\right)^{\psi}\right]-b B_{i}^{2}$ & $5^{5}$ \\
\hline \multirow[t]{5}{*}{ C-A model system } & $\mathrm{d} B_{i} / \mathrm{d} t=2 k \lambda_{1}\left(B_{i} / k\right)^{\alpha / 2} /\left\{\left[1+\lambda_{4} B_{T}\right]\left[1+\left(\lambda_{1} / \lambda_{2}\right) \exp \left(\lambda_{3} B_{L i}\right)\right]\right\}$ & $6^{1}$ \\
\hline & $\mathrm{d} B_{i} / \mathrm{d} t=\lambda_{1}\left(B_{i} / k\right)^{2}$ & $7^{2}$ \\
\hline & $\mathrm{d} B_{i} / \mathrm{d} t=\lambda_{1}\left(B_{i} / k\right)^{(\alpha+1) / 2} /\left[1+\lambda_{4} B_{i}\right]$ & $8^{3}$ \\
\hline & $\mathrm{d} B_{i} / \mathrm{d} t=\lambda_{1}\left(B_{i} / k\right)^{(\alpha+1) / 2} /\left\{\left[1+\lambda_{2} \exp \left(\lambda_{3} B_{L i}\right)\right]\right\}$ & $9^{4}$ \\
\hline & $\mathrm{d} B_{i} / \mathrm{d} t=\lambda_{1}\left(B_{i} / k\right)^{(\alpha+1) / 2} /\left\{\left[1+\lambda_{4} B_{i}\right]\left[1+\lambda_{2} \exp \left(\lambda_{3} B_{L i}\right)\right]\right\}$ & $10^{5}$ \\
\hline \multirow[t]{5}{*}{ C-K model system } & $\mathrm{d} B_{i} / \mathrm{d} t=\alpha_{0} B_{i}^{1 / 2}+\alpha_{1} B_{i}^{1 / 2} \ln \left[\left(B_{i} / k\right)^{1 / 2}\right]+\alpha_{2} B_{i}^{(m+1) / 2}+\alpha_{3} B_{i}^{1 / 2} B_{O i}+\alpha_{4} B_{i}^{1 / 2} B_{L i}$ & $11^{1}$ \\
\hline & $\mathrm{d} B_{i} / \mathrm{d} t=\alpha_{\mathrm{I}}+\alpha_{0} B_{i}^{1 / 2}+\alpha_{1} B_{i}^{1 / 2} \ln \left[\left(B_{i} / k\right)^{1 / 2}\right]$ & $12^{2}$ \\
\hline & $\mathrm{d} B_{i} / \mathrm{d} t=\alpha_{\mathrm{I}}+\alpha_{0} B_{i}^{1 / 2}+\alpha_{1} B_{i}^{1 / 2} \ln \left[\left(B_{i} / k\right)^{1 / 2}\right]+\alpha_{2} B_{i}^{3 / 2}$ & $13^{3}$ \\
\hline & $\mathrm{d} B_{i} / \mathrm{d} t=\alpha_{\mathrm{I}}+\alpha_{0} B_{i}^{1 / 2}+\alpha_{1} B_{i}^{1 / 2} \ln \left[\left(B_{i} / k\right)^{1 / 2}\right]+\alpha_{4} B_{i}^{1 / 2} B_{L i}$ & $14^{4}$ \\
\hline & $\mathrm{d} B_{i} / \mathrm{d} t=\alpha_{\mathrm{I}}+\alpha_{0} B_{i}^{1 / 2}+\alpha_{1} B_{i}^{1 / 2} \ln \left[\left(B_{i} / k\right)^{1 / 2}\right]+\alpha_{2} B_{i}^{3 / 2}+\alpha_{4} B_{i}^{1 / 2} B_{L i}$ & $15^{5}$ \\
\hline
\end{tabular}

${ }^{1}$ Model as given in original publication expressed in terms of tree basal area growth rate and tree basal area; ${ }^{2}$ Part of model relating tree growth rate to tree size at the start of a growth period; ${ }^{3}$ Model with term added describing symmetric competitive processes; ${ }^{4}$ Model with term added describing asymmetric competitive processes; ${ }^{5}$ Full model with terms added describing both symmetric and asymmetric competitive processes

differ appreciably from stand to stand. The C-A system was applied to data collected from 9,000 ha of mountain beech (Fuscospora cliffortioides (Hook.f.) Heenan \& Smissen, also known as Nothofagus solandri var. cliffortioides (Hook.f.) Poole) forests of New Zealand, whilst the C-K model system was applied to data from European beech (Fagus sylvatica L.) and silver fir (Abies alba Mill.) collected from sites scattered over the forested areas of France.

All three model systems used terms to represent symmetric competition that involved, essentially, the basal areas of the trees in each plot in the data set (the terms $B, B_{T}$ and $B_{O i}$ in Eqs. 1, 6 and 11, respectively). In essence, this assumed that symmetric competition in any one stand was absolute and each tree took up the same amount of the below-ground resources required for growth. For the present work it was desired to apply the model systems in individual stands where symmetric competition could be considered as relative, when trees would take up resources at rates directly proportional to their sizes. Thus, the terms $B, B_{T}$ and $B_{O i}$ were simply replaced with tree size $\left(B_{i}\right)$ in the three models, leaving Eqs. 5, 10 and 15 as equivalent models with application to data from individual stands, rather than data pooled over many stands. All three models then included other terms that aimed to describe asymmetric competitive processes by taking values that were assuming that larger trees could access resources required for growth that were disproportionately large relative to their sizes; these were the terms $\left(B / B_{i}^{2 / 3}\right), \exp \left(\lambda_{3} B_{L i}\right)$ and $\left(B_{i}\right)^{1 / 2} B_{L i}$ in Eqs. 5,10 and 15 , respectively.

The set of models then considered here are shown in detail in Table 2. Equations 2, 7 and 12 include only the terms that the model authors had intended would reflect the relationship between growth rate and tree size. Equations 3, 8 and 13 are the same models, but with the terms added that aimed to describe symmetric competition. Equations 4, 9 and 14 have the terms added that aimed to describe asymmetric competition. Equations 5, 10 and 15 have both terms added to describe both forms of competitive processes.

\section{Data}

An example data set was used here that came from eight sets of measurements of seven plots in even-aged, monoculture forest of E. pilularis growing in sub-tropical eastern 
Table 3 Condition, before and after a growth period, of the eight measurements from seven example blackbutt plots used here

\begin{tabular}{|c|c|c|c|c|c|c|c|c|c|}
\hline \multirow{2}{*}{$\begin{array}{l}\text { Plot } \\
\text { No.* }\end{array}$} & \multicolumn{4}{|c|}{ At start of growth period } & \multicolumn{4}{|c|}{ At end of growth period } & \multirow{2}{*}{$\begin{array}{l}\text { Age when } \\
\text { last thinned } \\
\text { (a) }\end{array}$} \\
\hline & $\begin{array}{l}\text { Age } \\
\text { (a) }\end{array}$ & $\begin{array}{l}\text { Stocking } \\
\text { density } \\
\left(\text { stems ha }^{-1}\right)\end{array}$ & $\begin{array}{l}\text { Stand } \\
\text { basal area } \\
\left(\mathrm{m}^{2} \mathrm{ha}^{-1}\right)\end{array}$ & $\begin{array}{l}\text { Tree average } \\
\text { diameter } \\
(\mathrm{cm})\end{array}$ & $\begin{array}{l}\text { Age } \\
\text { (a) }\end{array}$ & $\begin{array}{l}\text { Stocking } \\
\text { density } \\
\left(\text { stems ha }^{-1}\right)\end{array}$ & $\begin{array}{l}\text { Stand } \\
\text { basal area } \\
\left(\mathrm{m}^{2} \mathrm{ha}^{-1}\right)\end{array}$ & $\begin{array}{l}\text { Tree average } \\
\text { diameter } \\
(\mathrm{cm})\end{array}$ & \\
\hline 1 & 2.5 & 822 & 4.4 & 8 & 3.5 & 822 & 8.9 & 11.3 & Unthinned \\
\hline 18 & 5.7 & 1196 & 27.7 & 16.8 & 6.6 & 1137 & 32.2 & 18.6 & Unthinned \\
\hline 1018 & 12 & 1988 & 21.2 & 11 & 13 & 1963 & 25.5 & 12.1 & Unthinned \\
\hline 1002 & 13 & 366 & 10.6 & 18.9 & 14 & 366 & 11.9 & 20.1 & 13 \\
\hline 1009 & 28 & 1321 & 52.7 & 20.4 & 32 & 1210 & 58.6 & 22.3 & Unthinned \\
\hline 1008 & 24 & 124 & 10.5 & 32.7 & 26 & 124 & 12.1 & 35 & 22 \\
\hline 1018 & 32 & 1691 & 56.7 & 18.7 & 37 & 1395 & 58.5 & 20.9 & Unthinned \\
\hline 1021 & 37 & 136 & 16.3 & 38.9 & 39 & 136 & 16.9 & 39.6 & 22 \\
\hline
\end{tabular}

* Plots 1 and 18 were from a plantation experiment. Others were from regrowth native forest

Fig. 1 Scatter plots of individual tree basal area growth rates against tree basal areas at the start of the growth period, for four of the example plots used here. Plots 1 a and 1009 b were unthinned, whilst plots 1002 c and $1008 \mathbf{d}$ had been thinned. Additional plot details are given in Table 3
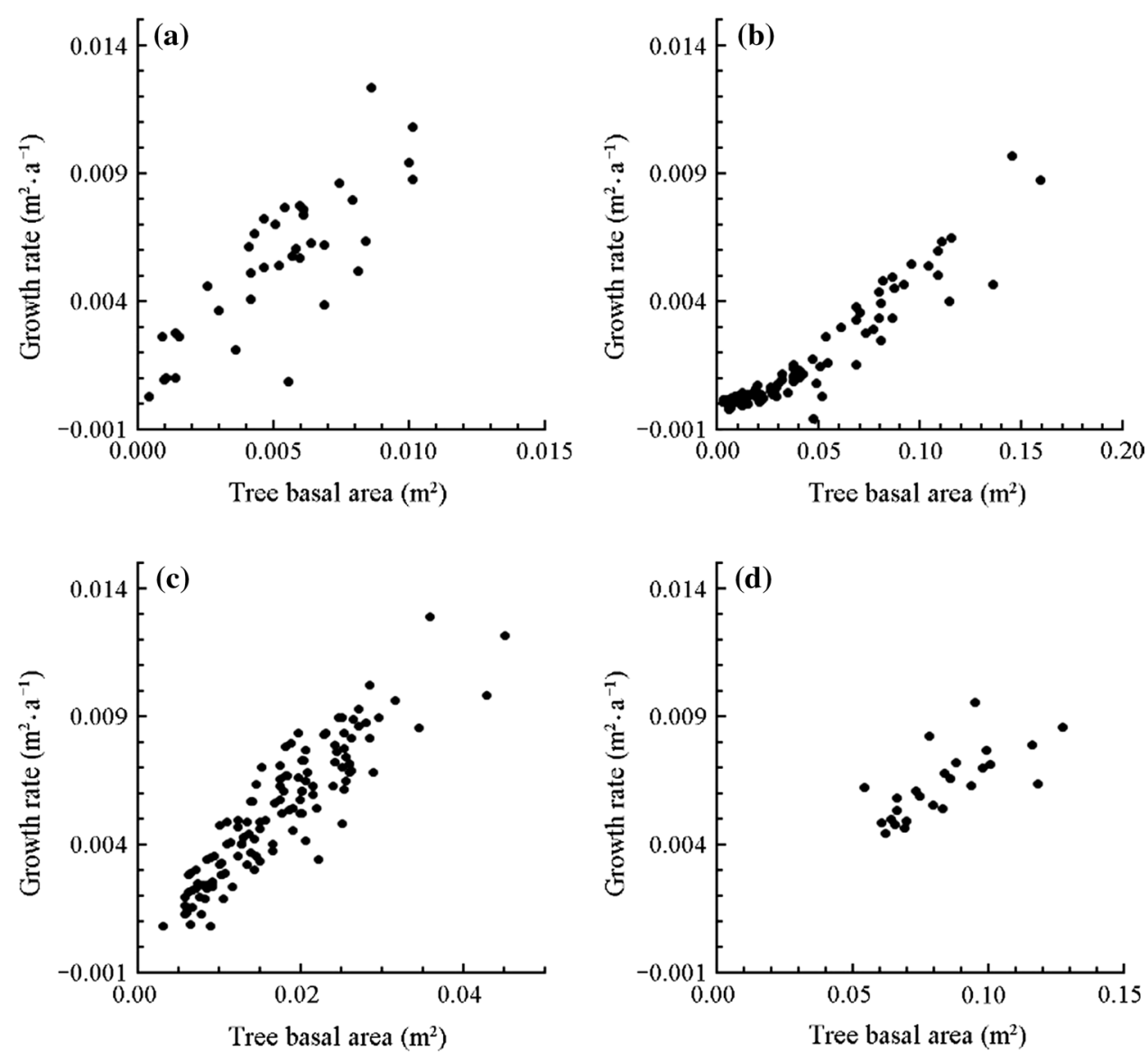

Australia. This is a species of commercial interest in the region and grows in both native forests and plantations. Data for six plots came from a collation of eucalypt forest data (Mattay and West 1994) and two from a plantation experiment (West and Smith 2019). Table 3 summarises the data used. Plot areas varied over the range $0.05-0.2$ ha. They were selected to have a wide range of ages and densities (degree of crowding of trees) so that different levels of tree growth and competitive interactions might be included. Before the measurement periods used, three of the older plots had been thinned from below by removal of about one half of their stand basal area; it is to be expected that intertree competitive interactions will be much reduced for some years following thinning. 
Figure 1 illustrates the variation in growth rate behaviour that occurred across the example plots. Note that the scale on the growth rate axis is the same in each case, illustrating that similar growth rates can occur right across the range of plot circumstances. However, the scale on the tree basal area axis differs widely between the plots, with trees not having grown nearly as large in the younger plots (1 and 1002) than in the older (1008 and 1009). The patterns of growth apparent in Fig. 1 are common in even-aged, monoculture forests; there are many examples of similar growth data from many different forest types around the world (e.g. West 1981a, b, 2018; West and Borough 1983; Perry 1985; Wichmann 2001; Pérot et al. 2010; Takahashi 2010; Pretzsch et al. 2012; Ishihara et al. 2016; Glencross et al. 2016; West et al. 2016; West and Smith 2019).

Subsequently, data from plot 1009 (Fig. 1b) are used to illustrate in detail how analyses were carried out with the data of all the plots. This plot was 0.081 ha in area and unthinned. It contained 107 trees when measured at 28 years of age. Over a subsequent five-year growth period, nine trees died. Its pattern of growth in Fig. 1(b) shows larger trees tending to grow faster than smaller, as is the usual effect of tree size on growth rate. As well, the presence of a group of smaller individuals, showing little or no growth, is consistent with the occurrence of asymmetric competitive processes, where larger trees were shading smaller and suppressing their growth. Of course, symmetric competitive processes may have been occurring at the same time to reduce growth rates of trees of all sizes from what they might have been if the trees were free of any competing neighbors. Note that some of the smaller trees in the plot had negative growth rates; this is often observed in forest growth data and usually arises through measurement errors of small changes or through stem shrinkage and swelling in response to differences in soil water availability at different times of measurement (Sheil 1995; Baker et al. 2002; Chitra-Tarak et al. 2015).

\section{Fitting and testing the models}

The data of Fig. 1 appear generally to be heteroscedastic in that the variation in growth rate tends to increase as tree basal area increases. The procedure REG of the SAS ${ }^{\circledR}$ statistical package ${ }^{1}$ was used to determine the ordinary leastsquares regression fit to the data of each example plot for each of the models used here that considered tree growth in relation to tree size (Eqs. 2, 7 and 12). Examination of the residuals from these regressions suggested that their

\footnotetext{
${ }^{1}$ Documentation for the SAS statistical package is available at https://support.sas.com/en/documentation.html (accessed August 2021).
}

variance increased as stem basal area increased and, in each case, could be described by the model.

$\sigma_{i}^{2}=\exp (p) B_{i}^{q}$

where, $\sigma_{i}^{2}$ was the variance $\left(\mathrm{m}^{4} \mathrm{a}^{-2}\right)$ of the residuals for a tree with stem basal area $B_{i}\left(\mathrm{~m}^{2}\right)$ and $p$ and $q$ were parameters. For plot 1009, values of $p$ and $q$, respectively, determined for Eq. 2 were -9.20 and 2.07, for Eq. 7 were -9.13 and 2.08 and, for Eq. 12 were -9.53 and 1.97. These, and similar functions for all the other example plots, were then used to provide weights for weighted least-squares regression in all subsequent regression analyses described below; the SAS procedure REG allows weighted least-squares regression to be done for linear models.

For all three model systems, the data of each example plot were used to apply weighted least-squares regression to the four versions of each model system as listed in Table 2, with and without the terms being used to describe competitive processes (Eqs. 2-5, 7-10, 12-15). In the cases of the A-W and C-A model systems with competitive process terms included, the models were nonlinear in their parameters and the weighted least-squares regressions were done using the NLIN procedure of the SAS package. This procedure offers four methods as options to solve the nonlinear least-squares problem, being the steepest-descent (gradient), Newton, modified Gauss-Newton or Marquardt methods. Trials suggested that occasionally one or other method led to a failure of the algorithm used to reach convergence. However, the Marquardt algorithm seemed to be consistently the most reliable and results reported here are for that method. All models of the C-K system fitted here (Eqs. 12-15) were linear in their parameters, so the REG procedure of SAS was used for those.

In the cases of the nonlinear versions of $\mathrm{A}-\mathrm{W}$ and $\mathrm{C}-\mathrm{A}$ model systems (Eqs. 3-5, 8-10), it is important to appreciate that, unlike linear regression, the methods used to solve nonlinear regression models do not provide unbiased estimators of either the parameters or the fitted values from the regression. This is recognized in what is termed 'intrinsic' and 'parameter effects' nonlinearity (Ratkowsky 1983, 1990). The former may lead to bias in estimates of the fitted values from the regression and their confidence limits (Ratkowsky 1983, Sect. 9.2). A high level of parameter effects nonlinearity may lead to substantial bias in estimates of the parameters (Ratkowsky 1983, Sect. 9.3); this is perhaps not of great importance, unless the estimates of the parameter values are to be used to draw some biological inference from the data, when any bias in them may lead to misleading conclusions. There may be a solution, often difficult, to the problems of parameter effects nonlinearity through re-parameterization of the model. As Ratkowsky (1983, Sect. 2.4) discussed, there are formal measures available that 
allow assessment of the degree of both these nonlinearities; the NLIN procedure of SAS determines those measures and they were considered here when nonlinear models were being fitted. Following Ratkowsky (1983, Sect. 2.4), if the measure of intrinsic or parameter effects nonlinearity exceeds the value $1 /(2 \sqrt{ } F)$, where $F=F(\kappa, \eta-\kappa ; \alpha)$ is obtained from the $F$-distribution for a model fitted with $\kappa$ parameters to a data set with $\eta$ observations and with a significance level $\alpha$, the nonlinearity may be considered statistically significant and, hence, the resulting biases may be significantly different from zero.

The objective of fitting the four versions of each model system was to determine the statistical significance of the inclusion in the model of the terms representing tree size and both symmetric and asymmetric competitive effects. The models including size effects only (Eqs. 2, 7 and 12) were fitted first; they are linear regressions and their goodness of fit was judged by their $r^{2}$ values and scatter plots of their residuals against their fitted values. Then, in each case, the respective terms to describe symmetric and/or asymmetric competitive processes were added to the model. Where nonlinear models are involved, as they were here, the most appropriate measure of their goodness-of-fit may be their root mean square error (the square root of the residual mean square) (e.g. Ratkowsky 2004). The statistical significance of the change in the root mean square error through adding a term to such a model (or to a linear model) may then be tested using the conventional 'extra sum-of-squares' $F$ test. Many studies of the effects of competitive process on forest growth behavior have been based on this type of testing (Nystrom and Kexi 1997; Gourlet-Fleury and Houllier 2000; Lessard et al. 2001; Mabvurira and Miina 2002; Mailly et al. 2003; Monty et al. 2008; Pérot et al. 2010; Pedersen et al. 2012; Carr et al. 2020; Barros de Oliveira et al. 2021). However, of recent times it has become common to use 'Akaike's Information Criterion' (AIC) (and allied criteria) to suggest which of a number of possible models is the most appropriate when fitted to a particular data set; a number of studies of competitive processes have used this method (Miina and Pukkala 2002; Canham et al. 2006; Canham and Uriarte 2006; Papaik and Canham 2006; Yang et al. 2009; Pretzsch 2021). Some studies have used both methods (Pommerening and Maleki 2014; Cordonnier and Kunstler 2015; Kahriman et al. 2018; Acquah and Marshall 2020; Bhandari et al. 2021) or, indeed, have used other methods altogether (Verzelen et al. 2006; Kuehne et al. 2019). However, the use of AIC does not provide a test of the statistical significance between model options (Canham and Uriarte 2006; Anderson 2008, Chap. 3) and so it was not the method favored here.
Table 4 Values of $r^{2}(\%)$ for terms designed to describe tree growth rate in relation to tree size only (Eqs. 2, 7 and 12) the fit to the data for each of the models used here that contained

\begin{tabular}{llll}
\hline Plot no. & \multicolumn{3}{l}{ Model system } \\
\cline { 2 - 4 } & A-W & C-A & C-K \\
\hline 1 & 92 & 78 & 79 \\
18 & 82 & 79 & 69 \\
1018 & 90 & 69 & 86 \\
1002 & 95 & 83 & 84 \\
1009 & 82 & 81 & 83 \\
1008 & 98 & 91 & 43 \\
1018 & 41 & 34 & 54 \\
1021 & 91 & 84 & 64 \\
\hline
\end{tabular}

Table 5 Residual mean square errors (all values here should be multiplied by $10^{-3}$ ) of the fit to the data for each of the models used here that contained terms designed to describe tree growth rate in relation to all of tree size and both symmetric and asymmetric competitive processes (Eqs. 5, 10 and 15)

\begin{tabular}{llll}
\hline Plot no. & \multicolumn{2}{l}{ Model system } \\
\cline { 2 - 4 } & A-W & C-A & C-K \\
\hline 1 & 3.46 & $3.46^{\mathrm{a}}$ & 3.51 \\
18 & $3.74^{\mathrm{a}}$ & $4.12^{\mathrm{a}}$ & $3.47^{\mathrm{a}}$ \\
1018 & 3.61 & $3.46^{\mathrm{a}}$ & $3.58^{\mathrm{a}, \mathrm{b}}$ \\
1002 & $3.46^{\mathrm{a}}$ & $3.32^{\mathrm{a}, \mathrm{b}}$ & 3.41 \\
1009 & $1.30^{\mathrm{a}, \mathrm{b}, \mathrm{c}}$ & $1.27^{\mathrm{a}, \mathrm{c}}$ & $1.26^{\mathrm{a}}$ \\
1008 & 4.00 & $2.97^{\mathrm{a}, \mathrm{b}}$ & $3.47^{\mathrm{a}}$ \\
1018 & 1.55 & $1.37^{\mathrm{a}, \mathrm{b}, \mathrm{c}}$ & 1.37 \\
1021 & 2.90 & $3.61^{\mathrm{a}}$ & 3.46 \\
\hline
\end{tabular}

Superscripts denote the statistical significance of reductions in the residual mean square error for model versions that included fewer terms

${ }^{a, b, c}$ Residual mean square error was reduced significantly $(p<0.05$ or smaller) from that of the corresponding model that included ${ }^{\text {a }}$ terms describing tree size effects only (Eqs. 2, 7 and 12), ${ }^{\mathrm{b}}$ terms describing tree size effects and symmetric competitive processes (Eqs. 3, 8 and 13) or ${ }^{c}$ terms describing tree size effects and asymmetric competitive processes (Eqs. 4, 9 and 14). If no superscript, there was no significant change of the residual mean square error from that of any of the other corresponding models

\section{Results}

As indicated by the $r^{2}$ values in Table 4, there was found to be a reasonably good fit to the data with the models that included only the terms that were attempting to describe tree size effects, averaging $76 \%$ over all models and plots. There was little difference between the A-W, C-A and C-K model systems in this respect.

Consideration was then given to the effects of adding the terms to the models that aimed to describe competitive processes. Table 5 shows the residual mean square error in each plot for the full models that included the terms describing size terms and both of the competitive processes (Eqs. 5, 10 
Table 6 For each of the example plot growth periods (see Table 3), values are shown of the intrinsic and parameter effects nonlinearities determined for the three nonlinear models fitted for the A-W and C-A model systems

\begin{tabular}{|c|c|c|c|c|c|c|}
\hline \multirow[t]{2}{*}{ Plot no. } & \multirow[t]{2}{*}{ Eq. no. } & \multicolumn{2}{|l|}{ A-W } & \multirow[t]{2}{*}{ Eq. no. } & \multicolumn{2}{|l|}{ C-A } \\
\hline & & Intrinsic & Parameter effects & & Intrinsic & $\begin{array}{l}\text { Param- } \\
\text { eter } \\
\text { effects }\end{array}$ \\
\hline \multirow[t]{3}{*}{1} & 3 & 0.86 & $>10$ & 8 & 3.41 & $>10$ \\
\hline & 4 & 0.66 & 3.37 & 9 & 0.55 & $>10$ \\
\hline & 5 & 6.89 & $>10$ & 10 & $>10$ & $>10$ \\
\hline \multirow[t]{3}{*}{18} & 3 & $<0.01$ & $>10$ & 8 & $>10$ & $>10$ \\
\hline & 4 & 0.18 & 0.36 & 9 & $>10$ & $>10$ \\
\hline & 5 & 1.36 & $>10$ & 10 & $>10$ & $>10$ \\
\hline \multirow[t]{3}{*}{1018} & 3 & 0.54 & $>10$ & 8 & 0.83 & $>10$ \\
\hline & 4 & 0.36 & 2.22 & 9 & $>10$ & $>10$ \\
\hline & 5 & $>10$ & $>10$ & 10 & $>10$ & $>10$ \\
\hline \multirow[t]{3}{*}{1002} & 3 & 0.36 & $>10$ & 8 & $>10$ & $>10$ \\
\hline & 4 & 0.23 & 1.01 & 9 & $>10$ & $>10$ \\
\hline & 5 & 2.11 & $>10$ & 10 & $>10$ & $>10$ \\
\hline \multirow[t]{3}{*}{1009} & 3 & $<0.01$ & $<0.01$ & 8 & $>10$ & $>10$ \\
\hline & 4 & $<0.01$ & $>10$ & 9 & $>10$ & $>10$ \\
\hline & 5 & $>10$ & 0.03 & 10 & $>10$ & $>10$ \\
\hline \multirow[t]{3}{*}{1008} & 3 & $>10$ & $>10$ & 8 & $>10$ & $>10$ \\
\hline & 4 & 2.67 & $>10$ & 9 & 0.80 & $>10$ \\
\hline & 5 & $>10$ & $>10$ & 10 & $>10$ & $>10$ \\
\hline \multirow[t]{3}{*}{1018} & 3 & $>10$ & $>10$ & 8 & $>10$ & $>10$ \\
\hline & 4 & 9.57 & $>10$ & 9 & 0.77 & $>10$ \\
\hline & 5 & $>10$ & $>10$ & 10 & $>10$ & $>10$ \\
\hline \multirow[t]{3}{*}{1021} & 3 & 0.02 & $>10$ & 8 & $>10$ & $>10$ \\
\hline & 4 & 0.33 & $>10$ & 9 & $>10$ & $>10$ \\
\hline & 5 & $>10$ & $>10$ & 10 & $>10$ & $>10$ \\
\hline
\end{tabular}

and 15). There tended to be quite small differences between the residual mean square errors of these models in each plot, suggesting that all three fitted the data equally well. Also indicated are the cases where the fit to the data of these full models was significantly better ( $p<0.05$ or smaller) than the fit to the data when some terms were omitted from each model; the extra sum of squares $F$ test was used for these tests. In some cases there was no significant improvement, although, especially in the C-A case, there often tended to be improvement when either or both terms describing the competitive processes were added to the model which included tree size terms only. However, even when the improvements were significant, they were often quite small. For the A-W and $\mathrm{C}-\mathrm{K}$ cases, including both competitive terms reduced the residual mean square error from the model with tree size terms only by an average of $5 \%$ over all the plots. For the $\mathrm{C}$-A case, the corresponding reductions were more appreciable, averaging $34 \%$. Once one or other of the competitive terms was included, adding the other tended to have a very small effect with an average reduction in residual mean square error over all plots of less than $1.5 \%$.
For those models that were nonlinear in their parameters (Eqs. 3-5, 8-10), the values of both the intrinsic and parameter effects measures of nonlinearity were often many times in excess of $0.2-0.3$, the values below which they needed to be for a non-significant ( $p=0.05$ or higher) departure from zero. Table 6 shows the cases where these significant departures occurred; of the 48 such models fitted, intrinsic nonlinearity was not significant in six cases and parameter effects in two cases, all eight being for the A-W system and none for the C-A system. The significant departures would explain why, as mentioned earlier, the nonlinear fitting procedures often had some difficulty reaching convergence. It suggests also that there might be substantial bias in the parameter values determined in these cases and/or the fitted values. However, the results of Fig. 2 for Plot 1009 suggest that the three models (Eqs. 5, 10 and 15) were reasonably unbiased estimators of growth rates even when potential existed for there to be bias in the fitted values estimates. Note also the quite modest scatter of the data around the 1:1 lines drawn there, suggesting that each model was a reasonably precise predictor of growth rates as suggested earlier. As shown 

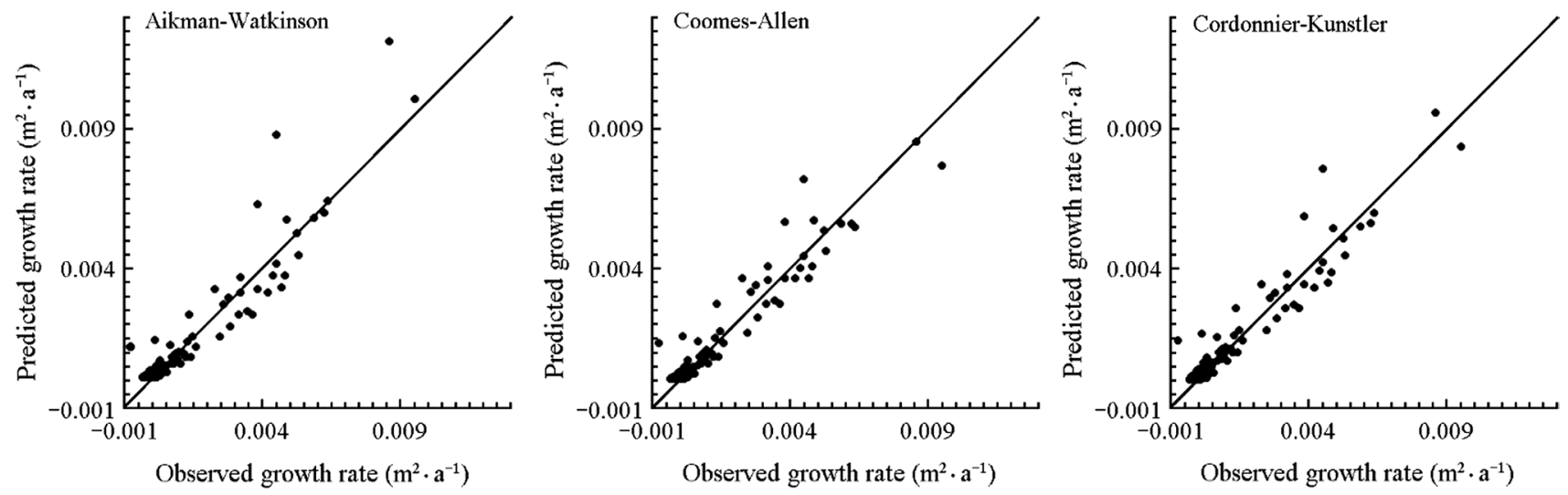

Fig. 2 For example plot 1009, and for each of the three model systems used here with the full models that included terms to describe tree growth rates in relation to tree size and both symmetric and asymmetric competitive processes (Eqs. 5, 10 and 15), scatter plots are shown of the fitted values of the model against the corresponding observed values. The solid lines are 1:1 lines on which all the points would lie if the model predicted growth exactly
Table 7 For the data of Plot 1009 , correlations between various design variables included in the 12 models being fitted here (Eqs. 2-5, 7-10, 12-15)

\begin{tabular}{|c|c|c|c|c|c|c|c|c|c|}
\hline \multirow[t]{2}{*}{ Design variables } & \multicolumn{4}{|c|}{$\begin{array}{l}\text { Terms excluding competitive pro- } \\
\text { cesses }\end{array}$} & \multicolumn{2}{|c|}{$\begin{array}{l}\text { Symmetric } \\
\text { competition } \\
\text { terms }\end{array}$} & \multicolumn{3}{|c|}{ Asymmetric competition terms } \\
\hline & $\mathrm{B}_{\mathrm{i}}^{2 / 3}$ & $\mathrm{~B}_{\mathrm{i}}^{2 / 3}$ & $\mathrm{~B}_{\mathrm{i}}^{2}$ & $\begin{array}{l}\mathrm{B}_{\mathrm{i}}^{1 / 2} \\
\ln \left[\left(\mathrm{B}_{\mathrm{i}} / \mathrm{k}\right)^{1 / 2}\right]\end{array}$ & $\mathrm{B}_{\mathrm{i}}$ & $\mathrm{B}_{\mathrm{i}}^{3 / 2}$ & $\bar{B} / B_{i}^{2 / 3}$ & $\exp (\mathrm{BLi})$ & $\mathrm{B}_{\mathrm{i}}^{1 / 2} \mathrm{BLi}$ \\
\hline $\mathrm{B}_{\mathrm{i}}^{1 / 2}$ & 1 & 0.998 & 0.895 & 0.999 & 0.983 & 0.944 & -0.896 & -0.975 & -0.056 \\
\hline $\mathrm{B}_{\mathrm{i}}^{2 / 3}$ & & 1 & 0.920 & 0.999 & 0.993 & 0.963 & -0.868 & -0.959 & -0.116 \\
\hline $\mathrm{B}_{\mathrm{i}}^{2}$ & & & 1 & 0.914 & 0.959 & 0.991 & -0.646 & -0.777 & -0.459 \\
\hline $\mathrm{B}_{\mathrm{i}}^{1 / 2} \ln \left[\left(\mathrm{B}_{\mathrm{i}} / \mathrm{k}\right)^{1 / 2}\right]$ & & & & 1 & 0.990 & 0.952 & -0.867 & -0.956 & -0.105 \\
\hline $\mathrm{Bi}$ & & & & & 1 & 0.986 & -0.795 & -0.905 & -0.243 \\
\hline $\mathrm{B}_{\mathrm{i}}^{3 / 2}$ & & & & & & 1 & -0.701 & -0.824 & -0.390 \\
\hline $\bar{B} / B_{i}^{2 / 3}$ & & & & & & & 1 & 0.951 & -0.342 \\
\hline $\exp (\mathrm{BLi})$ & & & & & & & & 1 & -0.177 \\
\hline $\mathrm{B}_{\mathrm{i}}^{1 / 2} \mathrm{BLi}$ & & & & & & & & & 1 \\
\hline
\end{tabular}

in the Supplementary Material, results for the other seven example plots were similar to these.

In least-squares regression analysis, the contribution of the various terms in a model to explaining the variation in the response variable (tree basal area growth rate in the present case) depends on the collinearity amongst the design (independent) variables. If one design variable has been included in the fitted model, addition to the model of another term that is substantially correlated with it will add little increase to the variation explained by the regression. This will occur no matter in which order the terms are added to the model. Thus, to consider the inter-relationships between the various design variables included in the models being fitted here, Table 7 shows the correlations between those variables for the case of Plot 1009. Most correlations are very high, with the exception of the ninth term, $B_{i}{ }^{1 / 2} B_{L i}$. That ninth term is used to

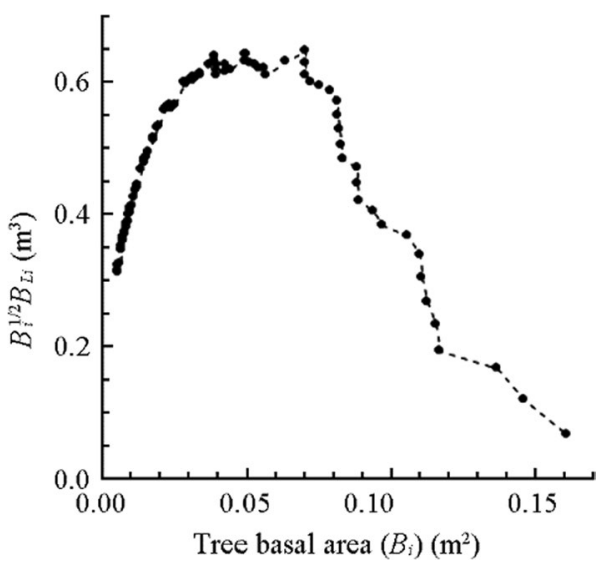

Fig. 3 Relationship between the design variable $B_{i}{ }^{1 / 2} B_{L i}$ and tree basal area $\left(B_{i}\right)$ for Plot 1009 
estimate how asymmetric competitive processes might be operating in the C-K model system (Eqs. 14 and 15). Its relationship with tree basal area in Plot 1009 is shown in Fig. 3. Amongst smaller trees, the increase apparent with increasing tree size is consistent with the effect expected with asymmetric competition. However, for larger trees, the decline with increasing tree size is the inverse of what might be expected. That is to say, in Plot 1009 this variable appeared to be a rather poor descriptor of what is expected of the asymmetric competitive process. The shape of the relationship makes it apparent also why the correlation of that variable with the others was low. As shown in the Supplementary Material, results for the collinearity between the design variables in the other seven example plots were mostly similar to those for Plot 1009 .

\section{Discussion}

The results suggested that, in the example forest stands considered here, the models tested served rather poorly to describe, separately, the effects on individual tree growth rates of each of tree size and symmetric and asymmetric competitive processes. Whilst the models were generally able to explain around three quarters of the variation in growth rates and to fit the data well (Fig. 2), there were practical problems with their use.

For the models that were nonlinear in their parameters, both the intrinsic and parameter effects nonlinearities were very often high (Table 6). Whilst reparameterization of a model might remove the parameter effects nonlinearity, this can be difficult to achieve in models with structures as complex as those here (Ratkowsky 1983 and 1990). However intrinsic nonlinearity is an inherent property of the modeldata set combination and cannot be removed. The consequences of these high levels of nonlinearity can be difficulties in achieving convergence of the methods used to fit the models as well as bias in estimates of the parameter values of the models and/or the fitted values from the models.

Even more problematic were the generally high correlations that existed between the design variables that were being used to describe each of tree size and competitive processes (Table 7). If design variables could be found that described each of those three effects specifically and that were uncorrelated with each other, then the degree of variation in growth rate explained separately by each of them could provide a quantitative measure of the extent to which each was affecting tree growth. These collinearities, and the inconsistent structure of the $B_{i}^{1 / 2} B_{L i}$ variable with the competitive process it was designed to describe (Fig. 3), suggest that the competitive process descriptors used here were linked inextricably with tree sizes. This means there is little likelihood that models of the nature of those considered here will be useful to segregate tree size and competitive process effects. Using data from mixed coniferous forests of Montana, USA, Contreras et al. (2011) showed how common were high levels of correlation between various indices that were describing the level of either symmetric or asymmetric competitive processes.

The apparent virtues of these model systems, as proposed in the publications in which they were devised (Aikman and Watkinson 1980; Coomes and Allen 2007; Cordonnier and Kunstler 2015), probably derive from the fact that they were either used in simulation studies only, hence not compared with observed data, or were applied to predict growth of individual trees that were scattered amongst many stands that varied in their circumstances across a large forest area. In that latter case, much of the variation in tree growth rates will be attributed to those varied stand circumstances, such as differences in their stocking densities, which may affect how competitive processes operate in different stands as much or more as between individual trees within any one stand.

The variables used to describe inter-tree competitive processes in the three model systems considered here were 'distance-independent' competition indices. Many studies have used 'distance-dependent' competition indices (e.g.Nyström and Kexi 1997; Mabvurira and Miina 2002; Miina and Pukkala 2002; Mailly et al. 2003; Pérot et al. 2010; Contreras et al. 2011; Pommerening and Maleki 2014; Kahriman et al. 2018; Kuehne et al. 2019; Carr et al. 2020; Lamonica et al. 2020; Barros de Oliveira et al. 2021) and have even included indices derived from aerial laser scanning (Pedersen et al. 2012). Models attempting to describe growth of individual trees commonly use distance independent or dependent indices to determine the extent to which either symmetric or asymmetric competitive processes are determining growth, but not the relative extent to which each is operating. It was the inclusion in the present models of terms which attempted to describe the effects of tree size and both competitive processes separately that recommended them to the present work; the hope was that quantification of the effects of the three might be determined separately.

There are a few other examples where indices describing both competitive processes, based on both distance-dependent and/or distance independent competition indices have been included jointly in a model (Gourlet-Fleury and Houllier 2000; Lessard et al. 2001; Larocque 2002; Mainwaring and Maguire 2004; Stoll and Newbery 2005; Monty et al. 2008; Bollandsås and Næsset 2009; Yang et al. 2009; Kuehne et al. 2019; Wang et al. 2021). However, in these cases, the degree of collinearity between the design variables used in the models does not seem to have been examined in detail and it probably confounded tree size and competitive effects in the same way as in the present work. 
In conclusion, it appears that despite their reputations as being useful in explaining tree growth behaviour, none of the model systems examined here could distinguish separately between the effects on individual growth rates of trees in a single stand of each of tree sizes and symmetric and asymmetric competitive processes. They were prevented from doing so both by collinearity between the terms used to describe each of the factors and technical problems involved in the use of nonlinear least-squares regression to fit the models to any one data set. Thus, they offer little opportunity to quantify the relative influences of these three processes on tree growth, information that would undoubtedly assist in the development of new model systems that may better describe tree growth.

Perhaps then, quite new approaches need to be devised if the effects on tree growth of tree size and competitive processes are to be quantified and modelled successfully. One approach that may have promise would initially involve derivation of a model that would describe size effects on individual tree growth rates for a species when trees were open-grown and not subject to competitive interactions with neighbors. A number of model systems have been based on that approach (e.g., Pommerening and Maleki 2014; Lamonica et al. 2020; Bhandari et al. 2021; Pretzsch 2021). Once that was determined, competition indices that describe above- and below-ground competitive processes separately might then be added to the system to attempt to quantify symmetric and asymmetric processes.

Open Access This article is licensed under a Creative Commons Attribution 4.0 International License, which permits use, sharing, adaptation, distribution and reproduction in any medium or format, as long as you give appropriate credit to the original author(s) and the source, provide a link to the Creative Commons licence, and indicate if changes were made. The images or other third party material in this article are included in the article's Creative Commons licence, unless indicated otherwise in a credit line to the material. If material is not included in the article's Creative Commons licence and your intended use is not permitted by statutory regulation or exceeds the permitted use, you will need to obtain permission directly from the copyright holder. To view a copy of this licence, visit http://creativecommons.org/licenses/by/4.0/.

\section{References}

Acquah SB, Marshall PL (2020) Assessing differences in competitive effects among tree species in central British Columbia. Canada Forests 11:167

Aikman DP, Watkinson AR (1980) A model for growth and self-thinning in even-aged monocultures of plants. Ann Bot 45:419-427

Anderson DR (2008) Model based inference in the life sciences. Springer Science+Business Media, NY

Baker TR, Affum-Baffoe K, Burslem DFRP, Swaine MD (2002) Phenological differences in tree water use and the timing of tropical forest inventories: conclusions from patterns of dry season diameter change. For Ecol Manage 171:261-274
Barros de Oliveira EKB, Rezende AV, Mazzei L, Murta LS, Castro RVO, d'Oliveira MVN, Barros Q (2021) Competition indices after reduced impact logging in the Brazilian Amazon. J Environ Manage 281:11898

Berger U, Piou C, Schiffers K, Grimm V (2008) Competition among plants: Concepts, individual-based modelling approaches, and a proposal for a future research strategy. Perspectives in Plant Ecol Evol Syst 9:121-135

Bhandari SK, Veneklaas EJ, McCaw L, Mazanec R, Whitford K, Renton $\mathrm{M}$ (2021) Individual tree growth in jarrah (Eucalyptus marginata) forest is explained by size and distance of neighbouring trees in thinned and non-thinned plots. For Ecol Manage 494:19364

Binkley D (2004) A hypothesis about the interaction of tree dominance and stand production through stand development. For Ecol Manage 190:265-271

Binkley D, Kashian DM, Boyden S, Kay MW, Bradford JB, Arthur MA, Fornwalt PJ, Ryan MG (2006) Patterns of growth dominance in forests of the Rocky Muntains, USA. For Ecol Manage 236:193-201

Bollandsås OM, Næsset E (2009) Weibull models for single-tree increment of Norway spruce, Scots pine, birch and other broadleaves in Norway. Scand J Forest Res 24:54-66

Bosela M, Kulla L, Roessiger J, Šebeň V, Dobor L, Büntgen U, Lukac M (2019) Long-term effects of environmental change and species diversity on tree radial growth in a mixed European forest. For Ecol Manage 446:293-303

Brown C, Oppon KJ, Cahill JF (2019) Species-specific size vulnerabilities in a competitive arena: Nutrient heterogeneity and soil fertility alter plant competitive size asymmetries. Funct Ecol 33:1491-1503

Burkhart HE, Tomé M (2012) Modeling forest trees and stands. Springer Science+Business Media, Dordrecht

Calama R, Conde M, de-Dios-García J, Madrigal G, Vázquez-Piqué J, Gordo FJ, Pardos M, (2019) Linking climate, annual growth and competition in a Mediterranean forest: Pinus pinea in the Spanish Northern Plateau. Ag for Meteorol 264:309-321

Canham CD, Papaik MJ, Uriarte M, McWilliams WH, Jenkins JC, Twery MJ (2006) Neighborhood analyses of canopy tree competition along environmental gradients in New England forests. Ecol App 16:540-554

Canham CD, Uriarte M (2006) Analysis of neighborhood dynamics of forest ecosystems using likelihood methods and modeling. Ecol Appl 16:62-73

Carr S, Larocque GR, Luckai N, Bell FW (2020) Effect of competition on individual white spruce production in young boreal mixedwood forests. Can J for Res 50:726-735

Chitra-Tarak R, Ruiz L, Pulla S, Dattaraja HS, Suresh HS, Sukumar R (2015) And yet it shrinks: a novel method for correcting bias in forest tree growth estimates caused by water-induced fluctuations. For Ecol Manage 336:129-136

Contreras MA, Affleck D, Chung W (2011) Evaluating tree competition indices as predictors of basal area increment in western Montana forests. For Ecol Manage 262:1939-1949

Coomes DA, Allen RB (2007) Effects of size, competition and altitude on tree growth. J Ecol 95:1084-1097

Copenhaver-Parry PE, Cannon E (2016) The relative influences of climate and competition on tree growth along montane ecotones in the Rocky Mountains. Oecologia 182:13-25

Cordonnier T, Bourdier T, Kunstler G, Piedallu C, Courbaud B (2018) Covariation between tree size and shade tolerance modulates mixed-forest productivity. Ann for Sci 75:1481-1492

Cordonnier T, Kunstler G (2015) The Gini index brings asymmetric competition to light. Perspectives in Pl Ecol Evol Syst $17: 107-115$

Cordonnier T, Smadi C, Kunstler G, Courbaud B (2019) Asymmetric competition, ontogenetic growth and size inequality drive the 
difference in productivity between two-strata and one-stratum forest stands. Theor Pop Biol 130:83-93

Craine JM, Dybzinski R (2013) Mechanisms of plant competition for nutrients, water and light. Funct Ecol 27:833-840

Fernández-Tschieder E, Binkley D (2018) Linking competition with growth dominance and production ecology. For Ecol Manage 414:99-107

Fernández-Tschieder E, Binkley D, Bauerle W (2020) Production ecology and reverse growth dominance in an old-growth ponderosa pine forest. For Ecol Manage 460:117891

Fien EKP, Fraver S, Teets A, Weiskittel AR, Hollinger DY (2019) Drivers of individual tree growth and mortality in an uneven-aged, mixed-species conifer forest. For Ecol Manage 449:117446

Forrester DI (2019) Linking forest growth with stand structure: tree size inequality, tree growth or resource partitioning and the asymmetry of competition. For Ecol Manage 447:139-157

Glencross K, West PW, Nichols JD (2016) Species shade tolerance affects tree basal area growth behaviour in two eucalypt species in thinned and unthinned even-aged monoculture. Aust for 69:157-167

Gourlet-Fleury S, Houllier F (2000) Modelling diameter increment in a lowland evergreen rainforest in French Guiana. For Ecol Manage 131:269-289

Guo Q, Chi X, Xie Z, Tang Z (2017) Asymmetric competition for light varies across functional groups. J Plant Ecol 10:74-80

Hajek P, Seidel D, Leuschner C (2015) Mechanical abrasion, and not competition for light, is the dominant canopy interaction in a temperate mixed forest. For Ecol Manage 348:108-116

Hodge A (2006) Plastic plants and patchy soils. J Exp Bot 57:401-411

Ishihara MI, Konno Y, Umeki K, Ohno Y, Kikuzawa K (2016) A new model for size-dependent tree growth in forests. PLoS ONE 11: e0152219

Kahriman A, Sahin A, Sonmez T, Yavuz M (2018) A novel approach to selecting a competition index: the effect of competition on individual-tree diameter growth of Calabrian pine. Can J for Res 48:1217-1226

Kuehne C, Weiskittel AR, Waskiewicz J (2019) Comparing performance of contrasting distance-independent and distancedependent competition metrics in predicting individual tree diameter increment. For Ecol Manage 433:205-216

Lamonica D, Pagel J, Valdés-Correcher E, Bert D, Hampe A, Schurr FM (2020) Tree potential growth varies more than competition among spontaneously established forest stands of pedunculate oak (Quercus robur). Ann for Sci 77:80

Larocque GR (2002) Examining different concepts for the development of a distance-dependent competition model for red pine diameter growth using long-term stand data differing in initial stand density. For Sci 48:24-34

Lei PF, Scherer-Lorenzen M, Bauhus J (2012) Belowground facilitation and competition in young tree species mixtures. For Ecol Manage 265:191-200

Lessard VC, McRoberts RE, Holdaway MR (2001) Diameter growth models using Minnesota forest inventory and analysis data. For Sci 47:301-310

Looney CE, D’Amato AW, Fraver S, Palik BJ, Frelich LE (2018) Interspecific competition limits the realized niche of Fraxinus nigra along a waterlogging gradient. Can $\mathrm{J}$ for Res 48:1292-1301

Mabvurira D, Miina J (2002) Individual-tree growth and mortality models for Eucalyptus grandis (Hill) Maiden plantations in Zimbabwe. For Ecol Manage 61:231-245

Mailly D, Turbis S, Pothier D (2003) Predicting basal area increment in a spatially explicit, individual tree model: a test of competition measures with black spruce. Can J for Res 33:435-443

Mainwaring DB, Maguire DA (2004) The effect of local stand structure on growth and growth efficiency in heterogeneous stands of ponderosa and lodgepole pine in central Oregon. Can J for Res 34:2217-2229

Marqués L, Camarero JJ, Zavala MA, Stoffel M, Ballasteros-Cánovas JA, Sancho-García C, Madrigal-González J (2021) Evaluating tree-to-tree competition during stand development in a relict Scots pine forest: how much does climate matter? Trees 35:1207-1219. https://doi.org/10.1007/s00468-021-02109-8

Mattay JP, West PW (1994) A collection of growth and yield data from eight eucalypt species growing in even-aged monoculture forest. CSIRO Division of Forestry, User Series No 18 CSIRO: Canberra. Available at http://sciwest.byethost6.com/Mattay/ 2020West/201994/20Eucalypt/20data/20CSIRO.pdf

Miina J, Pukkala T (2002) Application of ecological field theory in distance-dependent growth modelling. For Ecol Manage 161:101-107

Monty A, Lejeune P, Rondeux J (2008) Individual distance-independent girth increment model for Douglas-fir in southern Belgium. Ecol Mod 212:472-479

Mrad A, Manzoni S, Oren R, Vico G, Lindh M, Katul G (2020) Recovering the metabolic self-thinning and constant final yield rules in mono-specific stands. Frontiers in Forests and Global Change 3:62

Nong M, Leng Y, Xu H, Li C, Ou G (2019) Incorporating competition factors in a mixed-effect model with random effects of site quality for individual tree above-ground biomass growth of Pinus kesiya var langbianensis. NZ J for Sci 49:11

Nyström K, Kexi M (1997) Individual tree basal area growth models for young stands of Norway spruce in Sweden. For Ecol Manage 97:173-185

Ogawa K (2019) Scaling relations based on the geometric and metabolic theories in woody plant species: A review. Perspectives in Pl Ecol Evol Syst 40:125480

Orman O, Wrzesiński P, Dobrowolska D, Szewczyk J (2021) Regeneration growth and crown architecture of European beech and silver fir depend on gap characteristics and light gradient in the mixed montane old-growth stands. For Ecol Manage 482:118866

Papaik MJ, Canham CD (2006) Multi-model analysis of tree competition along environmental gradients in southern New England forests. Ecol App 16:1880-1892

Pedersen RO, Bollandsås OM, Gobakken T, Næsset E (2012) Deriving individual tree competition indices from airborne laser scanning. For Ecol Manage 280:150-165

Pérot T, Goreaud F, Ginisty C, Dhôte JF (2010) A model bridging distance-dependent and distance-independent tree models to simulate the growth of mixed forests. Ann for Sci 67:502

Perry DA (1985) The competition process in forest stands. In: Cannell MGR, Jackson JE (eds) Trees as crop plants. Inst of Terr Ecol, Abbots Ripton, Huntingdonshire, England. pp. 481-506

Pommerening A, Brzeziecki B, Binkley D (2016) Are long-term changes in plant species composition related to asymmetric growth dominance in the pristine Bialowieza Forest? Basic Appl Ecol 17:408-417

Pommerening A, Grabarnik P (2019) Individual-based methods in forest ecology and management. Springer Nature, Switzerland

Pommerening A, Maleki K (2014) Differences between competition kernels and traditional size-ratio based competition indices used in forest ecology. For Ecol Manage 331:135-143

Pommerening A, Meador AJS (2018) Tamm review: Tree interactions between myth and reality. For Ecol Manage 424:164-176

Pretzsch H (2021) Tree growth as affected by stem and crown structure. Trees 35:947-960

Pretzsch H, Biber P (2010) Size-symmetric versus size-asymmetric competition and growth partitioning among trees in forest stands along an ecological gradient in central Europe. Can J for Res 40:370-384 
Pretzsch H, Dieler J, Rotzer T (2012) Principles of growth partitioning between trees in forest stands under stress. In: Matyssek R, O $\beta$ wald W, Munch JC, Schnyder H, Ernst D, Pretzsch H (eds) Growth and defence in plants. Ecological Studies 220, Springer, Berlin. pp. 310-328

Pretzsch H, Schutze G, Biber P (2018) Drought can favour the growth of small in relation to tall trees in mature stands of Norway spruce and European beech. For Ecosys 5:20

Rasmussen CR, Weiner J (2017) Modelling the effect of size-asymmetric competition on size inequality: Simple models with two plants. Ecol Mod 343:101-108

Rasmussen CR, Weisbach AN, Thorup-Kristensen K, Weiner J (2019) Size-asymmetric root competition in deep, nutrient-poor soil. J Pl Ecol 12:78-88

Ratkowsky DA (1983) Nonlinear regression modeling. Marcel Dekker, NY

Ratkowsky DA (1990) Handbook of nonlinear regression models. Marcel Dekker, NY

Ratkowsky DA (2004) Model fitting and uncertainty. In: McKellar RC, $\mathrm{Lu}$ X (eds) Modeling microbial responses in food. CRC Press, Boca Raton, pp 151-196

Schenk HJ (2006) Root competition: beyond resource depletion. J Ecol 94:725-739

Sheil D (1995) A critique of permanent plot methods and analysis with examples from Budongo Forest, Uganda. For Ecol Manage 77:11-34

Stoll P, Newbery DM (2005) Evidence of species-specific neighborhood effects in the Dipterocarpaceae of a Bornean rain forest. Ecology 86:3048-3062

Takahashi K (2010) Effects of altitude and competition on growth and mortality of the conifer Abies sachalinensis. Ecol Res 25:801-812

Verzelen N, Picard N, Gourlet-Fleury S (2006) Approximating spatial interactions in a model of forest dynamics as a means of understanding spatial patterns. Ecol Complex 3:209-218

von Wuehlisch G, Muhs H-J, Geburek T (1990) Competitive behaviour of clones of Picea abies in monoclonal mosaics vs intimate clonal mixtures. A pilot study. Scand J for Res 5:397-401

Wang M, Zhao YH, Zhen Z, Jin XJ (2021) Individual-tree diameter growth model for Korean pine plantations based on optimized interpolation of meteorological variables. J Forestry Res 32:1535-1552

Weiskittel AR, Hann DW, Kershaw JA, Vanclay JK (2011) Forest growth and yield modelling. Wiley-Blackwell, Oxford
West PW (1981a) Comparative growth rates of several eucalypts in mixed-species stands in southern Tasmania. NZ J for Sci 11:45-52

West PW (1981b) Simulation of diameter growth and mortality in regrowth eucalypt forest of southern Tasmania. For Sci 27:603-616

West PW (2015) Tree and forest measurement, 3rd edn. Springer International Publishing, Switzerland

West PW (2018) Use of the Lorenz curve to measure size inequality and growth dominance in forest populations. Aust for 81:231-238

West PW (2020) Do increasing respiratory costs explain the decline with age in forest growth rate? J Forestry Res 31:693-712

West PW, Borough CJ (1983) Tree suppression and the self-thinning rule in a monoculture of Pinus radiata D. Don Ann Bot 52:149-158

West PW, Glencross K, Nichols JD (2016) Modelling growth behaviour in monoculture in subtropical eastern Australia of two eucalypt species that differ in shade tolerance. Southern Forests 78:283-287

West PW, Smith RGB (2019) Inter-tree competitive processes during early growth of an experimental plantation of Eucalyptus pilularis in sub-tropical Australia. For Ecol Manage 451:117450

Wichmann L (2001) Annual variations in competition symmetry in even-aged Sitka spruce. Ann Bot 88:145-151

Wu JN, Zeng HH, Zhao F, Chen CF, Jiang XJ, Zhu XA, Wang PY, Wu ZX, Liu WJ (2020) The nutrient status of plant roots reveals competition intensities in rubber agroforestry systems. Forests 11:1163

Yang Y, Huang S, Meng SX, Trincado G, Vanderschaaf CL (2009) A multilevel individual tree basal area increment model for aspen in boreal mixedwood stands. Can J for Res 39:2203-2214

Yokozawa M, Hara T (1992) A canopy photosynthesis model for the dynamics of size structure and self-thinning in plant populations. Ann Bot 70:305-316

Zhang X, Wang Z, Chhin S, Wang H, Duan A, Zhang J (2020) Relative contributions of competition, stand structure, age, and climate factors to tree mortality of Chinese fir plantations: Long term spacing trials in southern China. For Ecol Manage 465:118103

Publisher's Note Springer Nature remains neutral with regard to jurisdictional claims in published maps and institutional affiliations. 